\title{
The effect of cold adaptation on food-motivated behavior
}

\author{
ROBERT J. HAMM and FRED P. ROSEN \\ Virginia Commonwealth University, Richmond, Virginia 23284
}

\begin{abstract}
In order to investigate the relationship between physiological adaptation to the cold and behavioral responses for food while in the cold, groups of rats were exposed to either $-10^{\circ} \mathrm{C}$ or $21^{\circ} \mathrm{C}$ ambient temperatures. Exposures to the $-10^{\circ} \mathrm{C}$ temperature produced a physiological adaptation to the cold as indicated by a progressively smaller reduction in body temperature over days following cold exposure. After 16 days of 50-min temperature exposures, behavioral testing started. Subjects were placed in $-10^{\circ} \mathrm{C}$ environment and their barpress rates for food reinforcement were recorded. Results showed that the rats previously adapted to the cold responded more for food than rats not previously adapted to the cold. The physiological and behavioral effects of cold adaptation were not maintained after a 10-day retention period.
\end{abstract}

Adaptation to a stressor refers to the physiological tolerance acquired through repeated exposures to the stressor. While the physiological mechanisms involved in the adaptation process have been extensively investigated (Dill, 1964), until recently, this has not been the case in the study of the behavioral implications of adaptation to stress. One method several experimenters have used to investigate the behavioral effects of adaptation is an approach-avoidance conflict situation. For example, a number of experiments have shown that repeated exposures to gradually increasing levels of electric shock reduces the effects of subsequent intense aversive stimulation (e.g., Karsh, 1963; Miller, 1960). A similar effect has been found using cold water as the stressor (Hamm \& Riccio, 1968; Riccio \& Hamm, 1972).

The behavioral effects of adaptation have also been assessed using a behavioral thermoregulation procedure (Weiss \& Laties, 1961). For example, Laties and Weiss (1960) found that rats housed at $2^{\circ} \mathrm{C}$ began pressing a lever for heat reinforcement later in a 16 -h test session at $2^{\circ} \mathrm{C}$ than control subjects housed at $25^{\circ} \mathrm{C}$. Similarly, Revusky (1966) repeatedly exposed mice to a low environmental temperature and found that with successive cold exposures, fewer heat reinforcements were obtained. These two experiments suggest that as subjects adapt to the cold stress, they are less motivated to respond to produce heat reinforcement that reduces the cold stress. Two other experiments have not supported this interpretation. For example, rats housed at $2^{\circ} \mathrm{C}$ were found to obtain more heat reinforcement than noncold-exposed subjects (Carlton \& Marks, 1958). In addition, Baldwin and Ingram (1968) found

This research was supported by the Faculty Grant-In-Aid Program of Virginia Commonwealth University. Reprints may be obtained from the first author, Department of Psychology, Virginia Commonwealth University, Richmond, Virginia 23284. that mice housed at $10^{\circ} \mathrm{C}$ obtained more heat reinforcements than mice housed at $30^{\circ} \mathrm{C}$. Thus, the effects of cold adaptation are not consistently reflected in a reduction of the aversive properties of the cold ambient temperature.

A common characteristic of both the approachavoidance and the behavioral thermoregulation procedures for testing the behavioral implications of the adaptation process is that the behavior (i.e., the response) of the subject changes the frequency of aversive stimulation in the approach-avoidance situation or reduces the intensity of the stressor in the behavioral thermoregulation procedure. Thus, the assessment of the behavioral effects of adaptation may be confounded by the response modifying the stressor. The purpose of the present experiment was to test the generality of the behavioral consequences of adaptation by using a behavioral testing situation in which the response of the subject does not immediately change the impact of the stressor. A second purpose was to test the persistence of the behavioral and physiological effects of cold adaptation. More specifically, rats were reinforced with food for barpressing in a cold environment. The rationale for selecting cold as the stressor was that it provides a convenient physiological measure of the adaptation process (i.e., body temperature) that is independent of the behavioral measure. In addition, cold exposure is a stressor to which an increased physiological tolerance occurs in a short period (Riccio \& Campbell, 1966).

\section{METHOD}

\section{Subjects}

Subjects were 18 male albino rats of the Holtzman strain between the ages of 200 and 250 days old at the outset of the experiment. Ten days prior to the start of the experiment, rats were placed on a 23 -h food-deprivation regimen that maintained the rats at $80 \%$ of their free-feeding weights. 


\section{Apparatus}

A freezer with interior dimensions of $42 \times 60 \times 60 \mathrm{~cm}$ was used to maintain an air temperature of $-10^{\circ} \mathrm{C}$ or $21^{\circ} \mathrm{C}\left( \pm 1^{\circ} \mathrm{C}\right)$. A standard operant conditioning chamber manufactured by Scientific Prototype (Model D700-1305) was also used. The interior dimensions of the chamber were $23 \times 21 \times 19 \mathrm{~cm}$. A response bar was $3 \mathrm{~cm}$ above the grid floor and was centered on the front wall of the chamber. A force of $12 \mathrm{~g}$ was necessary to depress the response bar. A 45-mg food pellet dispenser was located $4 \mathrm{~cm}$ to the left of the response lever and $1 \mathrm{~cm}$ above the grid floor. A Yellow Springs Tele-Thermometer (Model 43TE) was used to record the colonic temperature of the rats. Solid state programming equipment was located in an adjacent control room, and this recorded responses and controlled food pellet delivery.

\section{Procedure}

The 18 rats were randomly assigned to two groups of 9 rats. In order to produce cold adaptation, the cold-adapted group was placed in the freezer at $-10^{\circ} \mathrm{C}\left( \pm 1^{\circ} \mathrm{C}\right)$ for $50 \mathrm{~min}$. Rats in the nonadapted group were placed for $50 \mathrm{~min}$ in the freezer with an internal temperature of $21^{\circ} \mathrm{C}$. All rats were placed in the freezer while in their home cages. After each 50-min exposure to the appropriate air temperature, the colonic temperature of each rat was recorded by inserting the Yellow Springs TeleThermometer probe approximately $2 \mathrm{~cm}$ into the colon. This procedure was followed for 16 days (Days 1-16).

On Days 14-16 rats in both groups were placed in the operant chamber and were trained to barpress on a continuous reinforcement schedule for a $45-\mathrm{mg}$ food pellet. This behavioral training took place at room temperature $\left(21^{\circ} \mathrm{C}\right)$ outside the freezer and approximately $1 \mathrm{~h}$ before each daily temperature exposure. On the basis of response rates on Days 15 and 16, matched pairs of subjects were formed. This was accomplished by matching the rat with the highest response rate in the coldadapted group with the rat in the nonadapted group with the highest response rate. This process was followed until all animals were matched with an appropriate animal in the other group.

The initial behavioral test for the effects of adaptation was conducted on Day 17, when the operant chamber was placed inside the freezer. The internal temperature of the freezer was $-10^{\circ} \mathrm{C}$. Rats from both groups were then placed for $50 \mathrm{~min}$ in the operant chamber inside the freezer. Response rates were recorded while the subjects responded for food in the cold environment. The colonic temperature of the rats was also recorded after the 50-min behavioral test.

After 10 days (Days 18-27) of no treatment in which neither group was removed from its home cages, rats were again tested for the behavioral effects of cold adaptation. The rats were again placed in the operant chamber inside the freezer with a procedure identical to the first behavioral test day (Day 17).

\section{RESULTS}

The colonic temperature data are presented in Figure 1. As is clear from the figure, the exposure to the cold environment did produce a marked reduction in the colonic temperature of the cold-adapted animals. In the cold-adapted group, the colonic temperature continued to drop after Day 1 until Day 5. This continued drop may be attributed to the decrease in activity of the rats after the first few days in the novel freezer environment. Between Day 5 and Day 15, the colonic temperature of the cold-adapted subjects increased $(\mathrm{t}=6.96, \mathrm{p}<.01)$. Since previous research Riccio \& Campbell, 1966) has indicated that in adult

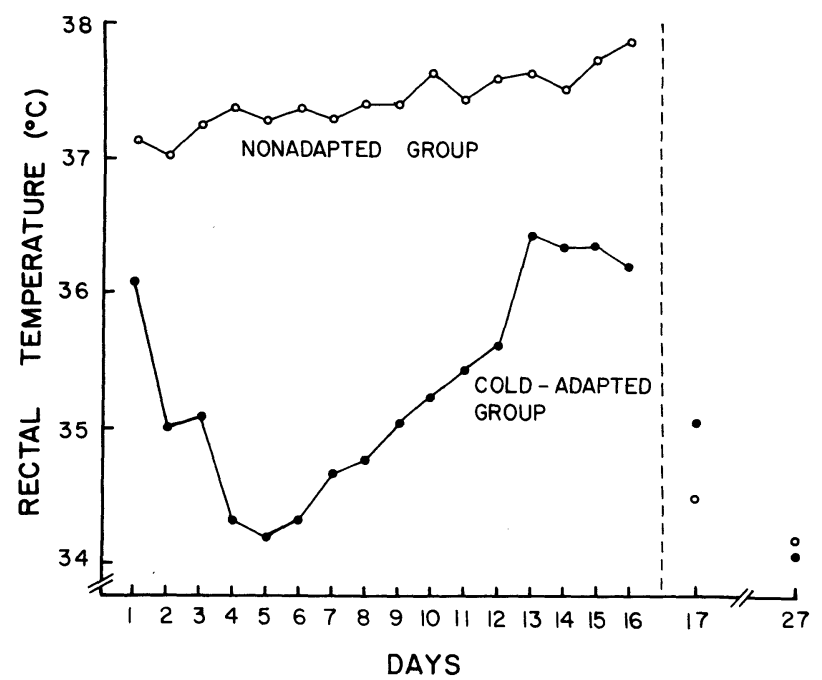

Figure 1. Mean rectal temperature immediately following $50 \mathrm{~min}$ in $-10^{\circ} \mathrm{C}$ ambient air temperature (cold-adapted group) and $21^{\circ} \mathrm{C}$ ambient air temperature (nonadapted group). Behavioral testing took place on Days 17 and 27.

rats the amount of increased growth over a 2-week period has virtually no influence on the ability of rats to maintain body temperature, these changes in colonic temperature following cold exposure indicate a development of physiological adaptation to the cold stressor.

The behavioral data are presented in Figure 2. This figure shows that on Day 17, when the operant chamber was in the cold environment, the cold-adapted subjects showed a smaller reduction in responding than the nonadapted animals $(t=2.51, \mathrm{p}<.05)$. Since there was no difference in response rates between groups before testing due to the matching of groups, the difference

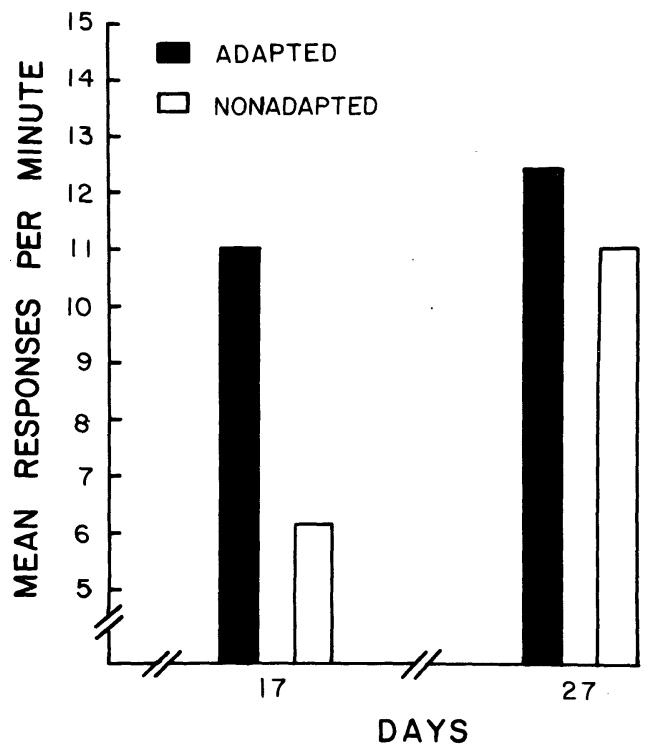

Figure 2. Mean response rates for food reinforcement for the cold-adapted and nonadapted groups on the first behavioral test day (Day 17) and on the retention test (Day 27). 
in response rates can be attributed to the differential effect that adaptation to a cold stressor has on responding in a cold environment. The colonic temperatures of the two groups during this behavioral testing were not significantly different, although the cold-adapted group had a higher mean temperature than the nonadapted rats (Figure 1, Day 17). After 10 days of no treatment (Day 27), there were no significant differences between groups in the behavioral test (Figure 2, Day 27) or in the colonic temperature (Figure 1, Day 27). Between Day 17 and Day 27, there was a significant increase in the response rates of the nonadapted subjects $(t=2.55$, $\mathrm{p}<.05)$.

\section{DISCUSSION}

The results clearly showed that coldexposed animals did physiologically adapt to the cold environment and that this physiological adaptation was initially correlated with a greater resistance to the disruption of food-motivated behavior during cold stress. In other words, the adaptation to the cold stressor did transfer and affect the performance of a task not immediately effective in reducing the stress. Thus, the data obtained on the first behavioral test extend the generality of the behavioral effects of stress adaptation to a behavioral testing situation where the behavior of the subject does not immediately modify the impact of the stressor. After a 10 -day retention period, neither the behavioral nor the body temperature differences between groups were retained.

One mechanism that has been proposed to account for the increased behavioral resistance to stress is based on a change in the set point for judging the stressor (Satinoff \& Henderson, 1977). According to this point of view, the repeated exposures to the stressor result in a change in the set point from which the aversive properties of the stressing stimulus are assessed. In terms of the present experiment, the cold-adapted subjects would have a shift in the set point of judging the coldness of the ambient temperature to a lower temperature than the nonadapted subjects. As a consequence, the cold-adapted subjects would not have their behavior disrupted as much by the $-10^{\circ} \mathrm{C}$ test temperature as the nonadapted subjects. Thus, this interpretation successfully explains the behavioral differences between groups on the first behavioral test day. The temporal interval between the cold exposures and the behavioral test $(23 \mathrm{~h})$ makes a temperature contrast effect based entirely upon sensory end organ changes unlikely. A shift in an internal referent as proposed by Helson's (1964) adaptation-level theory or by set point of Satinoff and Henderson (1977) is more likely the source of the mediation of the behavioral effects.

The retention test response rate data, however, pose a problem for this interpretation. If the higher response rate of the cold-adapted subjects was due to a change in the set point for assessing stress induced by the cold, the behavioral data on the second test day (Day 27) presents a problem. If over the 10-day retention interval, there was an increase in the set point for cold in the cold-adapted subjects toward the precold exposure level, then the cold-adapted group's response rate should decrease to the level of the nonadapted group's response rate. However, as can be seen from Figure 2, the nonsignificant difference in response rates on Day 27 was due to the increase in the nonadapted group's response rate rather than a decrease in the cold-adapted group's response rate. Thus, an interpretation of the results based solely on changes in set point for judging the aversiveness of the cold as a result of the adaptation process cannot explain the retention test results.

An adequate explanation of both the first behavioral test and the retention test results requires the application of not only changes in the set point for judging the stressor (Satinoff
\& Henderson, 1977), but also the Terris (Terris, German, \& Enzie, 1969; Terris \& Wechkin, 1967) mechanism, which emphasizes the discriminative role the stressor may play. Terris and his colleagues suggest that, during exposure to aversive stimuli, the internal cues produced by the stressor became associated with reinforced responding. As such, these stressorproduced stimuli become discriminative stimuli for reinforced responding and therefore maintain responding during the stressor. Thus, on the first test day, the stressor has not been associated with reinforced responding, and it cannot function as a discriminative stimulus. Consequently, the higher response rate of the cold-adapted subjects may reflect the change in the set point for assessing the aversiveness of the cold. After the first behavioral test, however, the cold stressor may have acquired discriminative properties, since both groups were reinforced for responding during the stressor. Thus, during the retention test, any difference remaining between groups in terms of a physiological adaptation of a modification in the set point may be offset by the discriminative properties acquired by the cold stressor on the first test day, and as a result, the cold-adapted and the nonadapted groups do not differ on the behavioral measure during the retention test. Thus, the present experiment suggests that the behavioral effects of the adaptation process depend on the interaction of the testing procedure (i.e., whether the stressor can function as a discriminative stimulus for responding) and the modification in the set point of the stressor produced by repeated exposures to the stressor.

\section{REFERENCES}

Baldwin, B. A., \& Ingram, D. L. The effects of food intake and acclimatization to temperature on behavioral thermoregulation in pigs and mice. Physiology \& Behavior, 1968, 3, 395-400.

Carlton, P. L., \& Marks, R. A. Cold exposure and heat reinforced operant behavior. Science, 1958, 128, 1344.

Dill, D. B. (Ed.). Handbook of physiology: Adaptation to the environment. Washington, D.C: American Physiological Society, 1964.

HАMм, R. J., \& Riccio, D. C. Adaptation to the punishing effects of cold water. Psychological Reports, 1968, 22, 1249-1254.

Helson, H. Adaptation-level theory. New York: Harper \& Row, 1964.

KARSH, E. B. Changes in intensity of punishment: Effect on running behavior of rats. Science, 1963, 140, 1084-1085.

LAties, V. G., \& Weiss, B. Behavior in the cold after acclimatization. Science, 1960, 131, 1891-1892.

Mille R, N. E. Learning resistence to pain and fear: Effects of overlearning, exposure, and rewarded exposure in context. Journal of Experimental Psychology, 1960, 60, 137-145.

REvUSKY, S. H. Cold acclimatization in hairless mice measured by behavioral thermoregulation. Psychonomic Science, 1966, 6, 209-210.

Riccio, D. C., \& Campbell, B. A. Adaptation and persistence of adaptation to a cold stressor in weanling and adult rats. Journal of Comparative and Physiological Psychology, 1966, 61, 406-410.

Riccio, D. C., \& HAMм, R. J. Increased resistance to punishment produced by adaptation to a cold stressor. Physiology \& Behavior, 1972, 9, 209-217.

Satinoff, E., \& Henderson, R. Thermoregulatory behavior. In W. K. Honig \& J. E. R. Staddon (Eds.), Handbook of operant behavior. Englewood Cliffs, N.J: Prentice-Hall, 1977.

Terris, W., German, D., \& Enzie, R. Transituational resistance to the effect of aversive stimulation. Journal of Comparative and Physiological Psychology, 1969, 67, 264-268.

Terris, W., \& Wechkin, S. Learning to resist the effects of punishment. Psychonomic Science, 1967, 7, 161-162.

Weiss, B., \& Laties, V. G. Behavioral thermoregulation. Science, $1961,133,1338-1344$.

(Received for publication April 19, 1979.) 